\title{
Echocardiography of the aortic valve
}

\section{I: Studies of normal aortic valve, aortic stenosis, aortic regurgitation, and mixed aortic valve disease ${ }^{1}$}

\author{
Özgen Feizi, Cecil Symons, and Magdi Yacoub \\ From the Departments of Cardiology, Royal Free Hospital, Lawn Road, London; The Middlesex Hospital, \\ London; and Harefield Hospital, Middlesex
}

Aortic valve echocardiography was performed in I05 subjects: 30 were healthy persons, 40 were patients with non-valvar heart disease, and 35 patients had isolated aortic valve disease. In the group with diseased aortic valves, the findings were correlated with observations at catheterization and in most cases at operation or necropsy.

The normal aortic valve echocardiogram is described and evidence is given that the anteriorly visualized cusp echoes are from the right coronary but those which are posteriorly visualized may be from the non-coronary or the left coronary cusp. The ultrasound patterns in aortic stenosis, aortic regurgitation, and mixed aortic valve disease are described. In each case the aortic root diameter was measured and cusp motion and thickness assessed by echocardiography. The ultrasound measurements of the aortic root correlated well with measurements at operation. Seventeen of the patients with aortic valve disease underwent aortic homograft replacement and were also studied after operation. The aortic homograft echocardiograms showed cusp movements indistinguishable from normal aortic valves.

It is concluded that echocardiography of the aortic valve is simple to perform, is of value diagnostically, and can contribute to the pre- and postoperative assessment of patients with aortic valve disease.

The aortic valve echocardiogram was first recorded by Edler et al. (196r), using excised calf heart preparation. Subsequently examples of normal human aortic valve echocardiograms were described (Edler, 1964; Effert et al., I964; Gramiak and Shah, 1968). Gramiak and Shah (1970) described the echocardiographic appearances of calcific aortic stenosis but found no characteristic pattern in aortic regurgitation. Hernberg, Weiss, and Keegan (1970) performed aortic valve echocardiography on patients with aortic valve disease; they could only infrequently record complete aortic valve echocardiograms and were unable to show any consistent pattern. Thus the value of aortic valve echocardiography has to date not been established. Furthermore, there has been no conclusive evidence for the anatomical identity of the visualized aortic valve cusps, though Edler (1964) postulated that the anteriorly and

Received 2I November 1973.

1 Presented in part at the British Cardiac Society Autumn 1972 meeting. posteriorly visualized cusp echoes originate from the right coronary and non-coronary cusps, respectively.

In this report the echocardiographic appearances of a large series of normal human aortic valves are described. The identity of the cusps was established by studies of two patients with senile degenerative aortic valve calcification in whom localized calcific deposits were used as markers. Echocardiographic studies of a further 33 patients with isolated aortic valve disease were performed in an attempt to define the patterns in aortic stenosis, aortic regurgitation, and mixed aortic valve disease.

\section{Subjects and methods}

Echocardiographic studies of the aortic valve were performed in 30 healthy persons (ages 18 to 35 ) with no symptoms or signs referable to the cardiovascular system and who were therefore assumed to have normal aortic valves. Forty patients (ages 35 to 56) had non-valvar heart disease ( 37 with coronary artery disease and 3 with thyroid dysfunction). In the group with non-valvar 
heart disease catheter-angiographic data of the aortic valves were available and were normal. Thirty-five other patients (ages 5 to 80 ) had isolated aortic valve disease. They were selected from a larger series because of the availability of catheter-angiographic data on 32 and postmortem information on 3 cases. Twenty-one of the patients with aortic valve disease subsequently underwent aortic valve replacement, when the extent of the aortic valve disease was assessed and when in II cases aortic root diameter was measured.

Echocardiograms were recorded according to the method of Gramiak and Shah (I968). An Ekoline 20 ultrasonoscope and a focused $2 \mathrm{~cm}$ diameter $2.25 \mathrm{mHz}$ transducer with a repetition rate of 1000 impulses per second were used. The patients were examined in the left lateral position, with the transducer applied over the third or fourth left intercostal space approximately $3 \mathrm{~cm}$ from the sternal edge. As an initial point of reference the echoes from the anterior mitral leaflet were identified. From this position the aortic valve echocardiogram could be obtained by directing the transducer medially towards the sternum and slightly superiorly towards the right shoulder. The ultrasonic patterns were viewed together with simultaneous electrocardiography on an oscilloscope using $M$ mode of display. The echocardiographic aortic root inner diameter was measured at the end of the $\mathbf{P}$ wave of the electrocardiogram and the systolic cusp echo separation (distance between the anteriorly and posteriorly visualized cusp echoes) was measured immediately after the $Q R S$ complex. Permanent recordings were made with a polaroid camera. A calibration scale on the oscilloscope enables measurements of dimensions of, and the distances between echo signals.

\section{Results}

Normal aortic valve echocardiogram

The normal aortic valve echocardiogram was seen within the aortic root as slender cusp echoes producing a box-like configuration during systole and a central line during diastole. Fig IA shows an echocardiogram from the base of the heart with simultaneous electrocardiogram. Fig. IB is a diagram of the cross-section through the base of the heart illustrating the presumed path taken by the ultrasound beam. On the echocardiogram, anteriorly there are prominent echo signals from the anterior chest wall and anterior right ventricular wall, posteriorly there are echoes from the posterior wall of the left atrium. The two parallel signals ( $\mathrm{Aa}$ and Ap) moving synchronously with the cardiac cycle are the echoes from the anterior and posterior walls
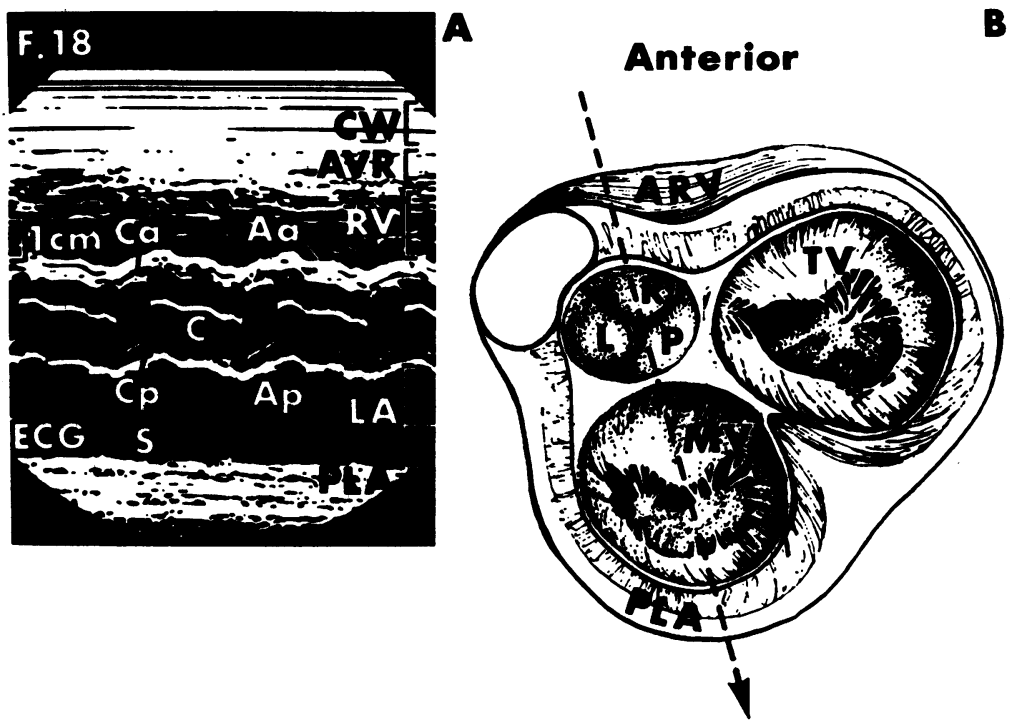

FIG. I ( $A$ ) Echocardiogram from the base of the heart, $C W$, chest wall; $A R V$ ar $A V R$, anterior right ventricular wall; $R V$, right ventricular cavity; $A a$ and $A p$, anterior and posterior aortic root walls; $C a$ and $C p$, echoes from the anteriorly and posteriorly positioned aortic valve cusps; $C$, aortic valve echoes during diastole; $L A$, left atrium; ECG, electrocardiogram; $S$, onset of ventricular systole; PLA, posterior left atrial wall. $(B)$ Diagram of transverse section of the base of the heart; dotted line indicates the presumed path taken by the ultrasound beam. Aortic valve cusps: $R$, right coronary; $L$, left coronary; and $P$, posterior; $M V$, mitral valve; $T V$, tricuspid valve. 
of the aortic root, respectively. The right ventricular and the left atrial cavities are visualized as relatively echo-free spaces between the anterior right ventricular wall and $\mathrm{Aa}$, and between $\mathrm{Ap}$ and the posterior wall of the left atrium, respectively. In the area representing the aortic root (between $\mathrm{Aa}$ and $\mathrm{Ap}$ ) are seen echoes originating from the aortic valve cusps. In diastole these are visualized as a single central line representing the cusps in the closed position. Frequently, when the gain of the instrument is reduced, the central line is visualized as two or three thin echo signals with hair line separation (I $\mathrm{mm}$ or less). At the onset of ventricular systole the central line is rapidly replaced by two parallel lines $\mathrm{Ca}$ and $\mathrm{Cp}$. These latter echoes which lie in close proximity to those from the inner wall of the aortic root represent the aortic valve cusps in the open position. At the onset of ventricular diastole the $\mathrm{Ca}$ and $\mathrm{Cp}$ come together to fuse and form the central line thus giving rise to the box-like configuration during systole.

In 22 of the 70 subjects with normal aortic valves, the typical box-like configuration was visualized (Fig. IA). In 36 cases the cusp signals were visualized only during systole and early diastole (Fig. $2 \mathrm{~A}$ ). In 3 instances only one cusp signal ( $\mathrm{Ca}$ or $\mathrm{Cp}$ ) could be obtained (Fig. 2B and $2 \mathrm{C}$ ). In 7 subjects, despite careful searching, incomplete valve echocardiograms were obtained. Only in 2 subjects was there complete failure to localize the aortic valve. Often very fine fluttering of the aortic valve echoes was seen during systole (Fig. 2D). The aortic root diastolic inner diameter measured in 68 of the subjects ranged from 19 to $25 \mathrm{~mm}$ (mean $23 \mathrm{~mm}$ ) and the systolic cusp echo separation ranged from 17 to 23 mm (mean $21 \mathrm{~mm}$ ).

\section{Identification of aortic valve cusp echoes using calcified deposits as markers}

Clinicopathological studies in 2 patients with circumscribed cusp lesions enabled identification of the echoes from individual aortic valve cusps. The first was a 69-year-old man with disseminated bronchogenic carcinoma in whom a soft ejection systolic murmur was heard over the aortic area. The aortic valve echocardiogram showed increased echo intensity and reduced movement of the anteriorly visualized cusp ( $\mathrm{Ca}$ ) (Fig. 3A). In contrast the posteriorly visualized cusp echo $(\mathrm{Cp})$ had normal intensity and movement. At necropsy, gross calcification was noted in the right coronary cusp and moderate calcification in the left coronary cusp. The non-coronary cusp was completely free of calcium deposition. No commissural fusion was present (Fig. 3B). It was concluded that the abnormal echo $\mathrm{Ca}$ was from the right coronary cusp as expected from its anterior anatomical location (Fig. IB) and the normal echo $\mathrm{Cp}$ originated from the non-coronary cusp.

The second patient was an 80-year-old man with chronic bronchitis and severe bronchopneumonia. Aortic valve echocardiogram showed increased intensity and reduced mobility of both cusp echoes $\mathrm{Ca}$
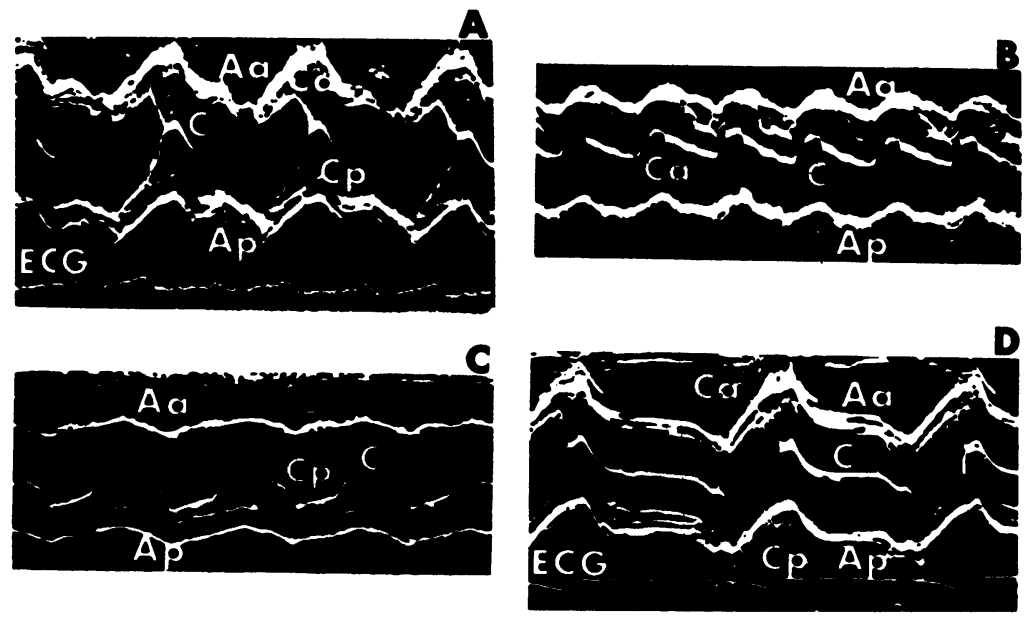

FIG. 2 Aortic root echocardiograms showing four additional patterns from normal aortic valves. In $A$, the aortic valve cusp echoes are visualized only during systole and early diastole. In Fig. $B$ and $C$ only one aortic valve cusp echo ( $C a$ and $C p$, respectively) is seen. $D$ shows fine systolic fluttering of the cusp echoes $\mathrm{Ca}$ and $\mathrm{Cp}$. Other symbols as in Fig. IA. 

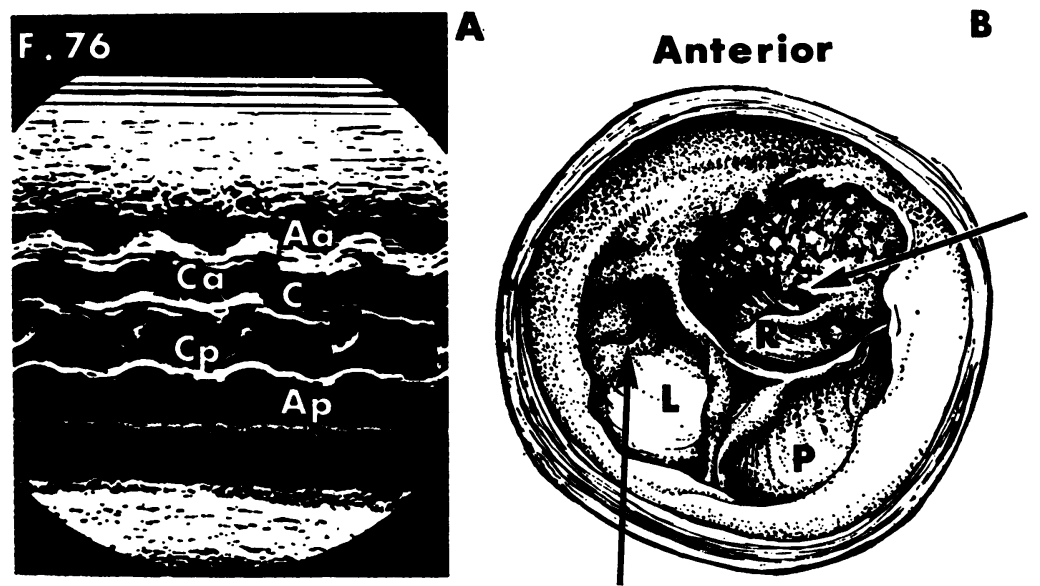

FIG. $3(A)$ Echocardiogram showing increased echo intensity and reduced movement of the anteriorly visualized aortic valve cusp $(C a)$. The posteriorly visualized cusp $(C p)$ shows normal intensity and movement. (B) Diagram of the aortic root as seen at necropsy. Arrows indicate calcification of the right and left coronary cusps. Other symbols as in Fig. I.

and $\mathrm{Cp}$ with multiple dense diastolic echoes $\mathrm{C}$ (Fig. 4A); in addition, minor echo signals were recorded from within the aortic root (Aa-Ap) area. At necropsy, calcium deposits were again noted only in the right and left coronary cusps as in the first patient. No commissural fusion was present; the inner aortic root wall showed small atheromatous plaques (Fig. 4B). It was concluded that the ab- normal $\mathrm{Ca}$ echo again represented the right coronary cusp; the Cp echo, which was abnormal in this instance, was presumably not from the unaffected non-coronary cusp but was from the calcified left coronary cusp.

It is, therefore, apparent that $\mathrm{Ca}$ represents the right coronary cusp while $\mathrm{Cp}$ may represent either the non-coronary or the left coronary cusp.
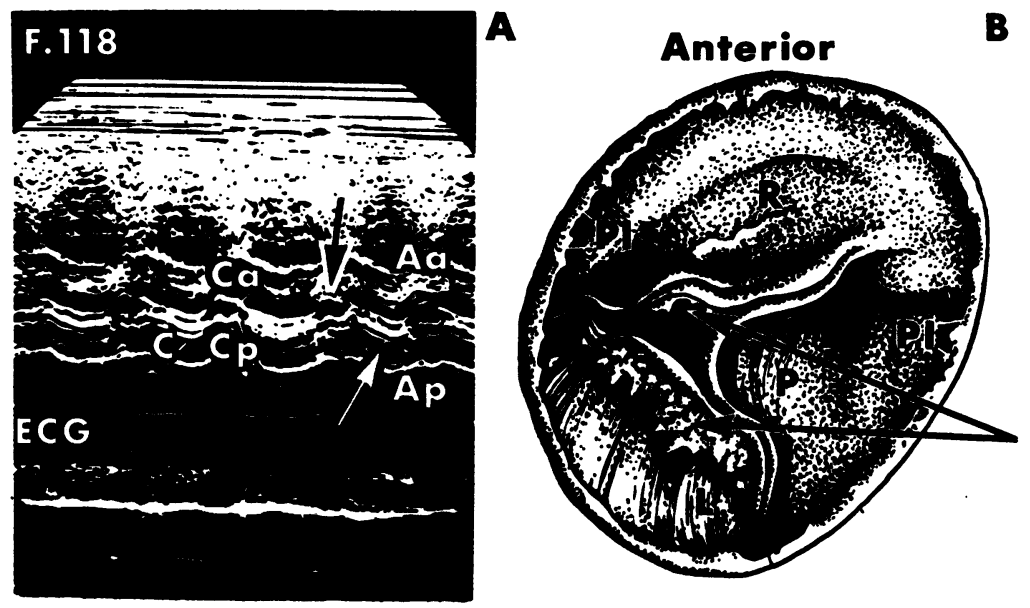

FIG. $4(A)$ Echocardiogram showing increased intensity and reduced mobility of both aortic cusp echoes, $C a$ and $C p$, and the multiple dense diastolic echoes $C$. Arrows indicate minor echo signals within the aortic root area. (B) Diagram of the aortic root at necropsy. Arrows indicate calcification of the right and left cusps. PI, atheromatous plaques in inner aortic root wall. Other symbols as in Fig. $I$. 
TABLE I Clinical, radiological, echocardiographic, catheter-angiographic, and operative findings in 8 patients with isolated aortic stenosis

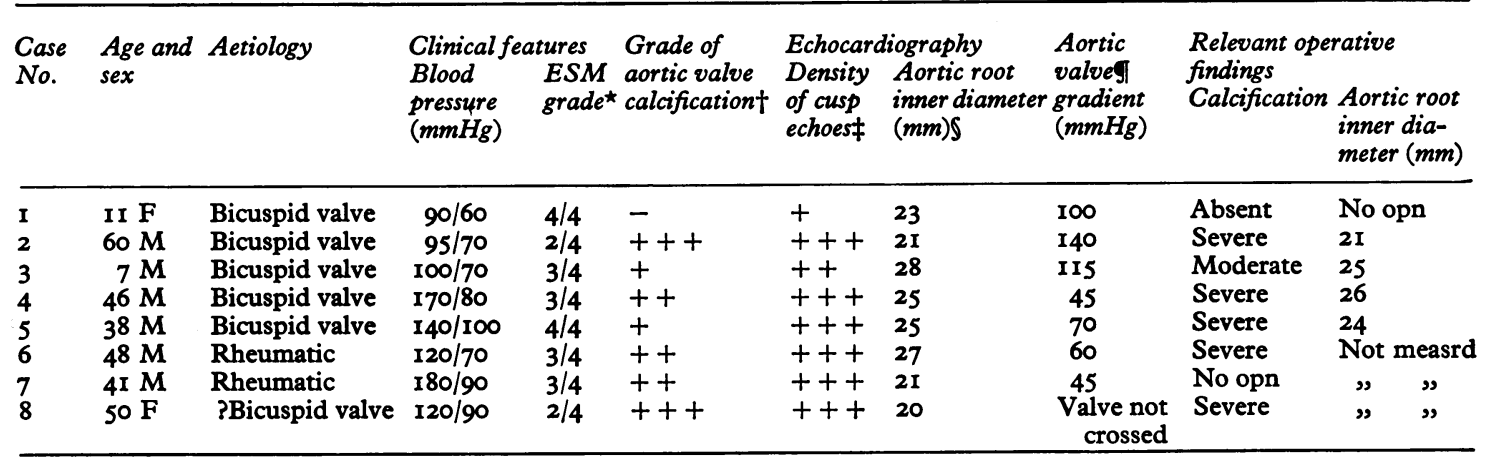

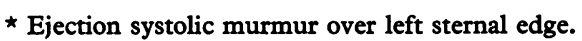

+ Grade of aortic valve calcification on screening: - Absent; + mild; ++ moderate; +++ severe.

$\neq$ Density of cusp echoes - thin cusp echoes; + broad cusp echoes; ++ dense echoes with some visible cusp signals; +++ very dense echoes with complete obliteration of cusp signals.

$\checkmark$ Diastolic aortic root inner diameter measured after the $P$ wave of the electrocardiogram.

I Systolic gradient across aortic valve at rest measured at catheter-angiography.

\section{Aortic stenosis}

Eight patients with isolated severe aortic stenosis were studied; 6 were male (ages 7 to 60 , mean 40) and 2 were female (ages II and 50). In 7 of the patients there was extensive cusp calcification; in only one patient (Case $I$, Table $I$ ) was the valve free of calcification. All but one patient subsequently underwent operation. The clinical, radiological, echocardiographic, catheter-angiographic, and operative data are summarized in Table $I$.

In the patient who had no valve calcification, the cusp signals were visualized only during systole and appeared wide, suggesting cusp thickening (Fig. 5A). The positions of the cusp echoes $\mathrm{Ca}$ and $\mathrm{Cp}$ in systole appeared normal, though at angiocardiography and at operation a severely stenosed and
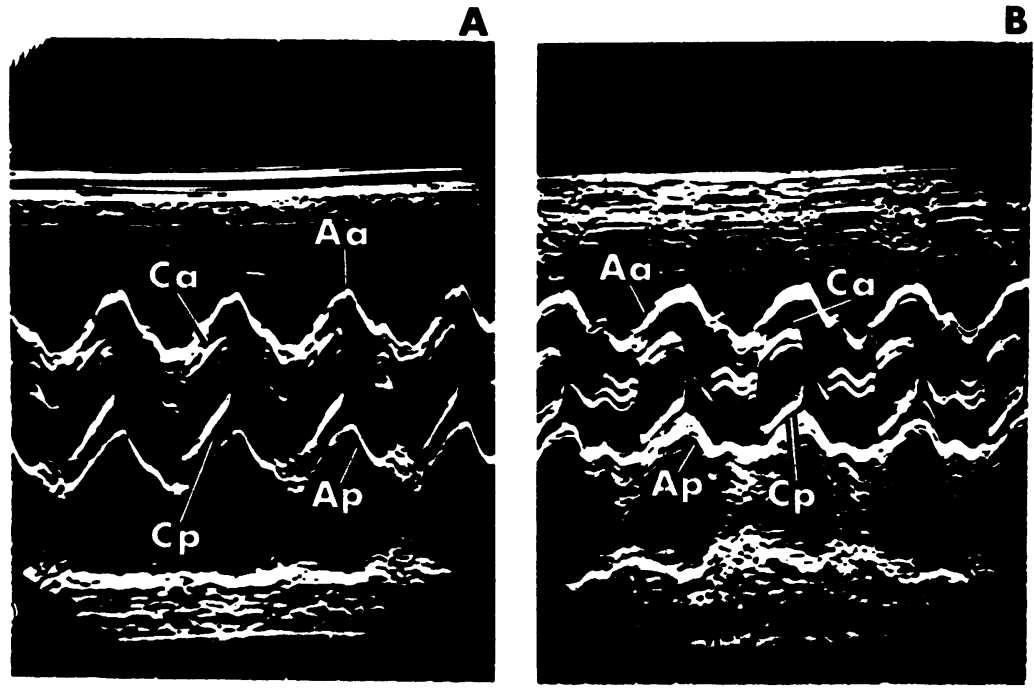

FIG. 5 ( $A$ ) Echocardiogram of patient with bicuspid aortic stenosis from the base of the heart showing wide cusp signals $C a$ and $C p$ during systole. (B) Aortic valve echocardiogram of the same patient after valvotomy. 

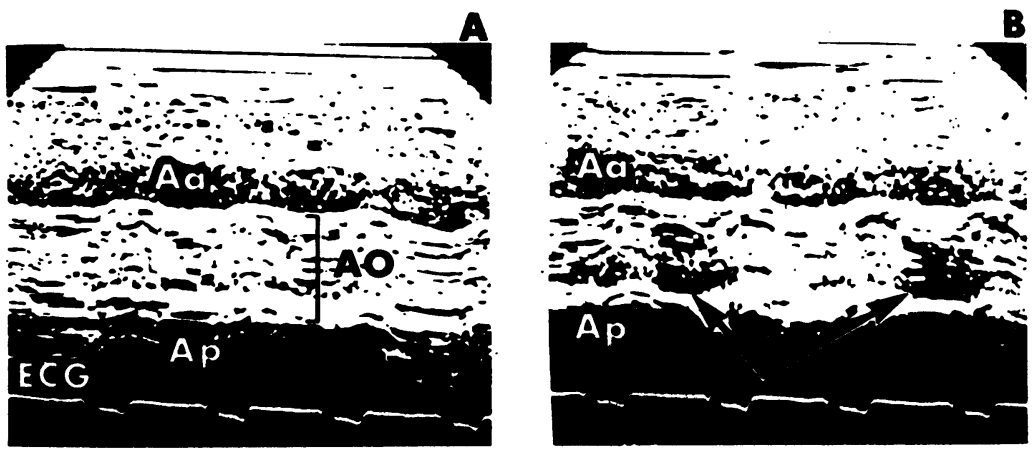

FIG. 6 Echocardiogram from the base of the heart in calcific aortic stenosis. $(A)$ Undamped recording: $A O$, echoes from the aortic valve. (B) Damped recording: arrows indicate the relatively echo-free spaces during systole. Other symbols as in Fig. I.

domed aortic valve was seen. The reduced separation of the cusp echoes in systole described in aortic stenosis by Feigenbaum (1972) was not seen. The apparently normal spacing of the cusp echoes during systole may be explained by the upward displacement of the domed orifice out of the reach of the ultrasound beam, allowing echo signals to be received from the wide base of the dome, below the stenosis. Fig. $5^{\mathrm{B}}$ shows the aortic valve echocardio- gram of this patient one week after valvotomy. The $\mathrm{Ca}$ and $\mathrm{Cp}$ echoes are thicker than normal as noted before operation, but they have assumed the normal box-like configuration during systole. There is diastolic cusp echo separation of $\mathrm{I} \cdot 5 \mathrm{~mm}$ suggesting some degree of aortic regurgitation.

In the remaining 7 patients with valve calcification the aortic valve echocardiographic patterns were similar; a typical example (Case 2, Table I) is

TABLE 2 Clinical, echocardiographic, catheter-angiographic, and operative findings in 15 patients with isolated aortic regurgitation

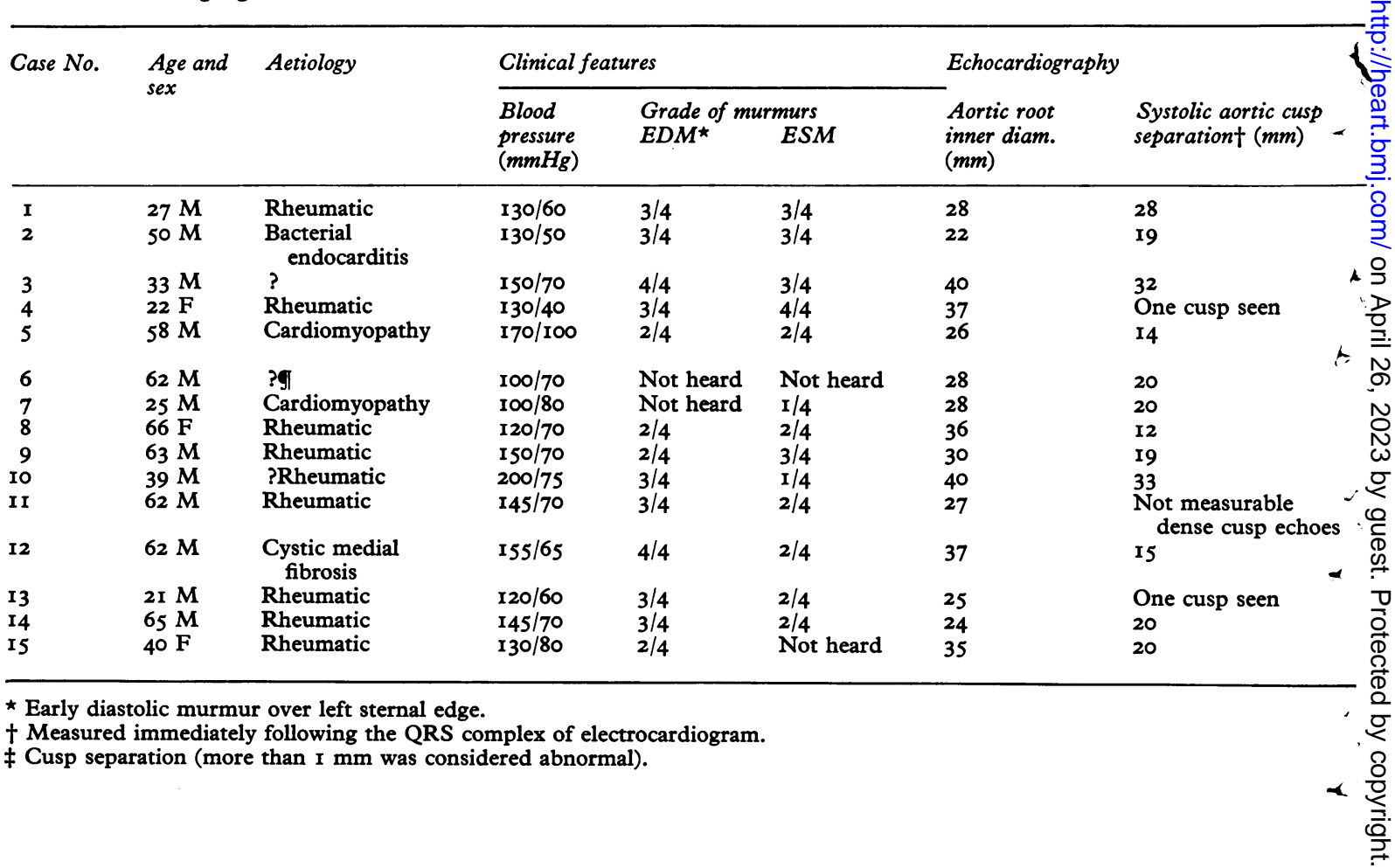


shown in Fig. 6A. The cusp signals were recorded as continuous multiple, thickened, bright echoes within the aortic root $(\mathrm{Aa}-\mathrm{Ap})$ area. When the gain of the ultranoscope was reduced, relatively echo-free spaces could be obtained during systole in 5 instances (Fig. 5B). This is probably caused by momentary shifting of the maximally calcified regions on the rigid aortic valve, out of the reach of the ultrasound beam, rather than by retained cusp mobility, since at the time of operation the aortic valves in all 6 operated patients showed gross calcific aortic stenosis with commissural fusion, and absent cusp movement. These findings suggest that the extensive valve calcification is responsible for the dense echoes.

\section{Aortic regurgitation}

Fifteen patients with isolated aortic regurgitation were studied: I2 were male (ages 21 to 65 , mean 47), and 3 were female (ages 22 to 66, mean 43). The clinical, echocardiographic, catheter-angiographic, and, where available, anatomical data are summarized in Table 2.

The most striking echocardiographic features obtained in Io of the 15 patients were abnormal separation of the two cusp echoes during diastole and increased echo intensity suggesting cusp thickening. A typical example is shown in Fig. 7A. Two of the patients with thickened cusp signals also showed moderate restriction of cusp movement as in Fig. 7B. Catheter-angiography in these 2 patients confirmed restricted cusp movement, and subsequent examination of the aortic valves (Cases 5 and 8, Table 2) revealed thickening of the middle part of each cusp with mild cusp shortening and no fusion of the commissures. The cusps were noted to be mobile but the shortening prevented apposition. Coarse systolic oscillations of the cusp echoes (7 patients) such as those illustrated in Fig. $7 \mathrm{C}$, an increase in the aortic root diameter (12 patients), and increased systolic separation of the cusp echoes (3 patients) were further additional but nonspecific features in patients with aortic regurgitation.

In 5 patients in this group, diastolic cusp separation was not seen. In 2 of these (Cases 4 and 13, Table 2), only the anteriorly positioned cusp echoes could be obtained, showing restricted movement and abnormal anterior position during diastole instead of the usual central position (Fig. $7 \mathrm{E}$ ). At operation extreme shrinkage of all three cusps was observed with gross aortic regurgitation. It is therefore not surprising that good cusp echoes were unobtainable in these 2 patients because cusp tissue was lacking. In the third of the 5 patients (Case 3,

\begin{tabular}{|c|c|c|c|c|}
\hline \multirow{2}{*}{$\begin{array}{l}\text { itolic aortic } \\
\text { separation } \ddagger\end{array}$} & \multirow{2}{*}{$\begin{array}{l}\text { Catheter-angio- } \\
\text { graphic grade of } \\
\text { regurgitation }\end{array}$} & \multicolumn{3}{|c|}{ Operative findings } \\
\hline & & \multicolumn{2}{|c|}{$\begin{array}{l}\text { Aortic root inner } \\
\text { diam. }(\mathrm{mm})\end{array}$} & Relevant pathology $\S$ \\
\hline sent & $4 / 4$ & \multicolumn{2}{|c|}{ Not measured } & \multirow{2}{*}{$\begin{array}{l}\text { Perforated right and non-coronary cusps } \\
\text { Left cusp destroyed by vegetations }\end{array}$} \\
\hline$\underset{\lambda}{\operatorname{sent}}$ & $3 / 4$ & " & 》 & \\
\hline ent & $4 / 4$ & \multicolumn{2}{|l|}{41} & \multirow{3}{*}{$\begin{array}{l}\text { Large cusps and large central orifice } \\
\text { Extreme shrinkage of cusps } \\
\text { (Necropsy finding: middle part of each cusp thickened and cusps mildly } \\
\text { shortened) }\end{array}$} \\
\hline ent & $4 / 4$ & \multicolumn{2}{|l|}{$\begin{array}{l}39 \\
25\end{array}$} & \\
\hline sest & $2 / 4$ & \multicolumn{2}{|l|}{25} & \\
\hline sent & $\mathbf{r} / 4$ & \multicolumn{2}{|c|}{ Not measured } & \multirow{6}{*}{$\begin{array}{l}\text { No opn } \\
\text { No opn } \\
\text { Middle part of each cusp thickened and cusps mildly shortened } \\
\text { No opn } \\
\text { No opn } \\
\text { No opn }\end{array}$} \\
\hline jent & $I / 4$ & " & " & \\
\hline ient & $3 / 4$ & " & " & \\
\hline ient & $4 / 4$ & " & " & \\
\hline ent & $3 / 4$ & " & " & \\
\hline snt & $4 / 4$ & ", & ", & \\
\hline ent: & $4 / 4$ & \multicolumn{2}{|l|}{39} & Free aortic regurgitation with floppy cusps \\
\hline $\begin{array}{l}\text { ent } \\
\text { ent }\end{array}$ & $\begin{array}{l}4 / 4 \\
4 / 4\end{array}$ & \multicolumn{2}{|c|}{$\begin{array}{l}24 \\
\text { Not measured }\end{array}$} & $\begin{array}{l}\text { Much shortened and thickened cusps } \\
\text { Mildly shortened cusps with tear of free margin of right coronary cusp }\end{array}$ \\
\hline ent & $2 / 4$ & 川 & " & No opn \\
\hline
\end{tabular}

the aortic valves inspected at operation were tricuspid. ivestigated for ischaemic heart disease. ir symbols as in Table $\mathrm{I}$. 


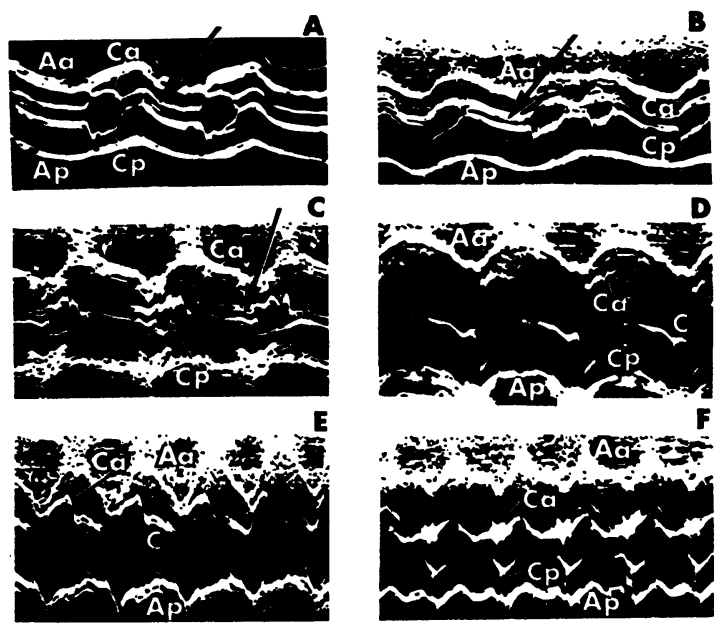

FIG. 7 Six aortic root echocardiograms showing aortic valve patterns from patients with isolated aortic regurgitation. Arrows indicate the abnormal diastolic cusp separation. Increased intensity of cusp echoes is shown in Fig. $A, B$, and $C$. In $B$, cusp movements are restricted and $\mathrm{Ca}$ and $\mathrm{Cp}$ do not reach as far as the inner aortic root wall. Fig. $7 C$ shows pronounced systolic fluttering of the cusp echoes and dilated aortic root. $D$ shows normal aortic valve pattern and $a$ dilated aortic root. $E$ shows abnormally positioned $\mathrm{Ca}$ cusp echoes. $F$ shows early systolic fluttering affecting mainly the Ca cusp echoes.
Table 2) an aortic valve echocardiogram was obtained, which was apparently normal apart from some increase in the aortic root diameter (Fig. 7D). At operation free aortic regurgitation was confirmed, the aortic valve was tricuspid and there was some thickening of the leaflets. A large central orifice was present. The aortic valve echocardiogram in the fourth patient (Case 12, Table 2) showed unusual early systolic oscillations affecting mainly the anteriorly positioned cusp echoes. The posteriorly visualized cusp echoes showed an unusual configuration (Fig. $7 \mathrm{~F}$ ). At operation floppy aortic valve leaflets were noted. In the fifth patient (Case 6, Table 2) aortic valve calcification obscured the cusp signals and produced an echocardiographic pattern indistinguishable from that of calcific aortic stenosis.

\section{Mixed aortic valve disease}

Ten patients with mixed aortic valve disease were studied, 5 were male (ages II to 6r, mean 35) and 5 were female (ages 5 to 64, mean 26). The clinical, radiological, echocardiographic, catheter-angiographic, and operative data are summarized in Table 3.

In 4 of the Io patients the aortic valve echocardiogram showed diastolic cusp echo separation. Fig. 8A exemplifies a moderately calcified valve. The additional echoes distorting the cusp signals are presumably from the calcified foci. One of the four patients who showed diastolic cusp echo

TABLE 3 Clinical, radiological, echocardiographic, catheter-angiographic, and operative findings in ro patients with mixed aortic valve disease

\begin{tabular}{|c|c|c|c|c|c|c|c|c|c|c|c|c|c|}
\hline $\begin{array}{l}\text { Case } \\
\text { No. }\end{array}$ & $\begin{array}{l}\text { Age } \\
\text { and } \\
\text { sex }\end{array}$ & $\begin{array}{l}\text { Clinical } \\
\text { Blood } \\
\text { pressure }\end{array}$ & $\begin{array}{l}\text { features } \\
\text { Grade } \\
\text { murmu } \\
\text { EDM }\end{array}$ & $\begin{array}{l}\text { of } \\
\text { irs } \\
\text { ESM }\end{array}$ & $\begin{array}{l}\text { Grade of } \\
\text { aortic } \\
\text { valve } \\
\text { calcifica- } \\
\text { tion }\end{array}$ & $\begin{array}{l}\text { Echocar } \\
\text { Aortic } \\
\text { root } \\
\text { inner } \\
\text { diam. } \\
(\mathrm{mm})\end{array}$ & $\begin{array}{l}\text { liography } \\
\text { Diastolic } \\
\text { cusp } \\
\text { separa- } \\
\text { tion }\end{array}$ & $\begin{array}{l}\text { Density } \\
\text { of cusp } \\
\text { echoes }\end{array}$ & $\begin{array}{l}\text { Catheter- } \\
\text { Aortic } \\
\text { valve } \\
\text { gradient } \\
(\mathrm{mm} H \mathrm{~g})\end{array}$ & $\begin{array}{l}\text {-angiography } \\
\text { Grade of } \\
\text { aortic } \\
\text { regurgita- } \\
\text { tion }\end{array}$ & $\begin{array}{l}\text { Operati } \\
\text { Aortic } \\
\text { root } \\
\text { inner } \\
\text { diam. } \\
(\mathrm{mm})\end{array}$ & $\begin{array}{l}\text { ve findings } \\
\text { Calcifica- } \\
\text { tion }\end{array}$ & Relevant pathology \\
\hline $\mathbf{I}$ & $51 \mathrm{~F}$ & $140 / 60$ & $2 / 4$ & $3 / 4$ & ++ & 30 & D & +++ & 100 & $2 / 4$ & n.m. & Severe & $\begin{array}{l}\text { Severely stenotic } \\
\text { rigid valve }\end{array}$ \\
\hline 2 & $51 \mathrm{~F}$ & $130 / 80$ & $4 / 4$ & $2 / 4$ & - & 38 & Present & ++ & 140 & $2 / 4$ & n.m. & Moderate & Main lesion stenosis \\
\hline 3 & $51 \mathrm{M}$ & $\begin{array}{l}170 / 80 \\
100 / 70\end{array}$ & $3 / 4$ & $2 / 4$ & + & 22 & & $++t$ & 60 & $2 / 4$ & n.m. & No opn & \\
\hline $\begin{array}{l}4 \\
5\end{array}$ & $\begin{array}{rl}5 & \mathrm{~F} \\
\text { II } \mathrm{M}\end{array}$ & $\begin{array}{l}100 / 70 \\
120 / 80\end{array}$ & n.h. & $3 / 4$ & - & 16 & Present & & 40 & $I / 4$ & n.m. & & \\
\hline $\begin{array}{l}5 \\
6\end{array}$ & I I $M$ & & $3 / 4$ & $2 / 4$ & - & 20 & Present & + & 45 & $I / 4$ & n.m. & No opn & \\
\hline 6 & 61 M & $180 / 70$ & $3 / 4$ & $4 / 4$ & ++ & 32 & Present & ++ & 15 & $4 / 4$ & 33 & Moderate & $\begin{array}{l}\text { Main lesion } \\
\text { regurgitation }\end{array}$ \\
\hline 7 & 4I M & $160 / 60$ & $3 / 4$ & $I / 4$ & + & 34 & D & $++t$ & $\begin{array}{l}\text { Valve } \\
\text { not } \\
\text { crossec }\end{array}$ & n.m. & n.m. & Severe & $\begin{array}{l}\text { Severely stenotic } \\
\text { rigid valve }\end{array}$ \\
\hline 8 & $60 \mathrm{~F}$ & $120 / 60$ & $3 / 4$ & $I / 4$ & +++ & 20 & D & $++t$ & 90 & $I / 4$ & 24 & Severe & $\begin{array}{l}\text { Severely stenotic } \\
\text { rigid valve }\end{array}$ \\
\hline 9 & I4 M & $110 / 70$ & $3 / 4$ & $2 / 4$ & - & 30 & $\begin{array}{l}\text { One } \\
\text { cusp } \\
\text { seen }\end{array}$ & + & 70 & $I / 4$ & n.m. & Nil & $\begin{array}{l}\text { Floppy valve and } \\
\text { long eccentric } \\
\text { orifice }\end{array}$ \\
\hline ro & $64 \mathrm{~F}$ & $140 / 60$ & $4 / 4$ & $3 / 4$ & +++ & 21 & D & +++ & 100 & $3 / 4$ & n.m. & Severe & $\begin{array}{l}\text { Severely stenotic } \\
\text { rigid valve }\end{array}$ \\
\hline
\end{tabular}




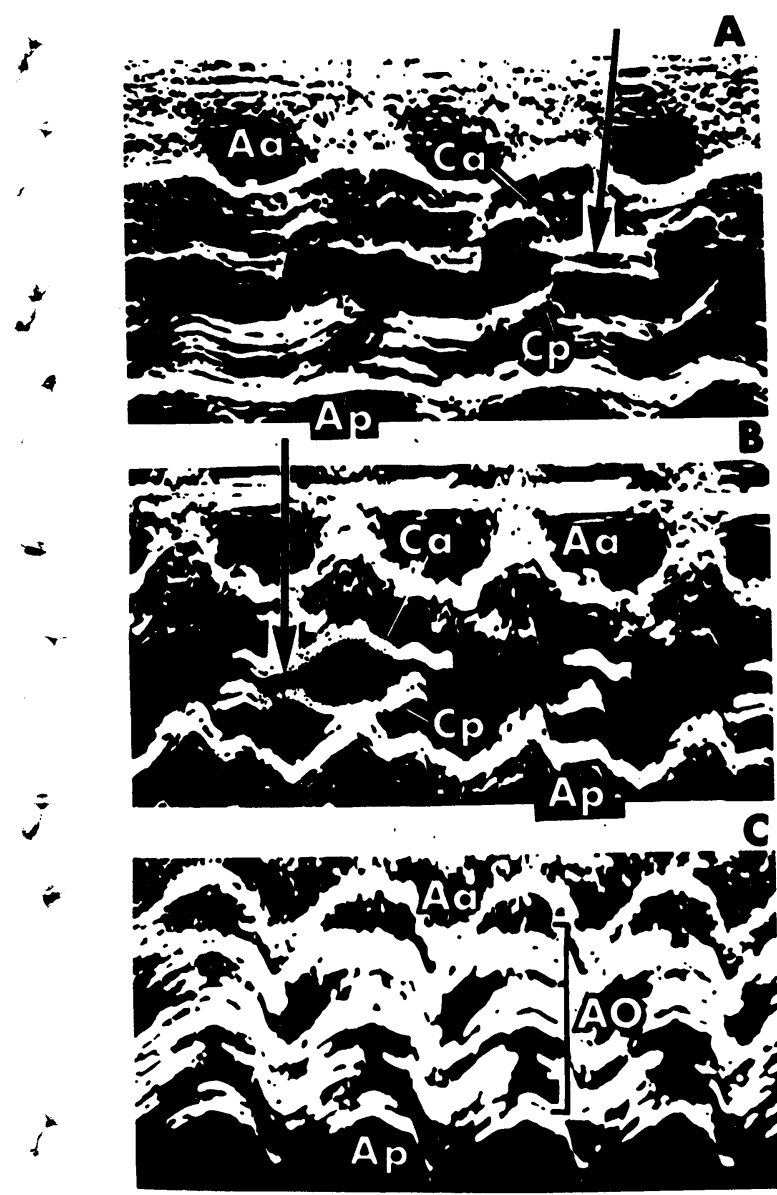

FIG. 8 Three aortic root echocardiograms from patients with mixed aortic valve disease. $(A)$ Shows abnormal diastolic cusp separation (arrowed). (B) Shows restricted cusp movement and diastolic separation of $\mathrm{Ca}$ and $\mathrm{Cp}$ echoes (arrowed). (C) Shows dense cusp echoes $A O$ due to severe calcification.

separation (Case 5, Table 3) had wide cusp signals and restricted movement on the echocardiogram (Fig. 8B). There was no detectable aortic valve calcification on cardiac screening. In one patient (Case 9, Table 3) only one cusp signal was recorded; in the remaining 5 patients in this group with mixed aortic valve disease, aortic valve calcification obscured the cusp echoes. Fig. 8C exemplifies a heavily calcified valve echocardiogram which is indistinguishable from those 9 patients with calcific aortic stenosis.

\section{Homograft valve}

Echocardiographic study was also carried out on 17

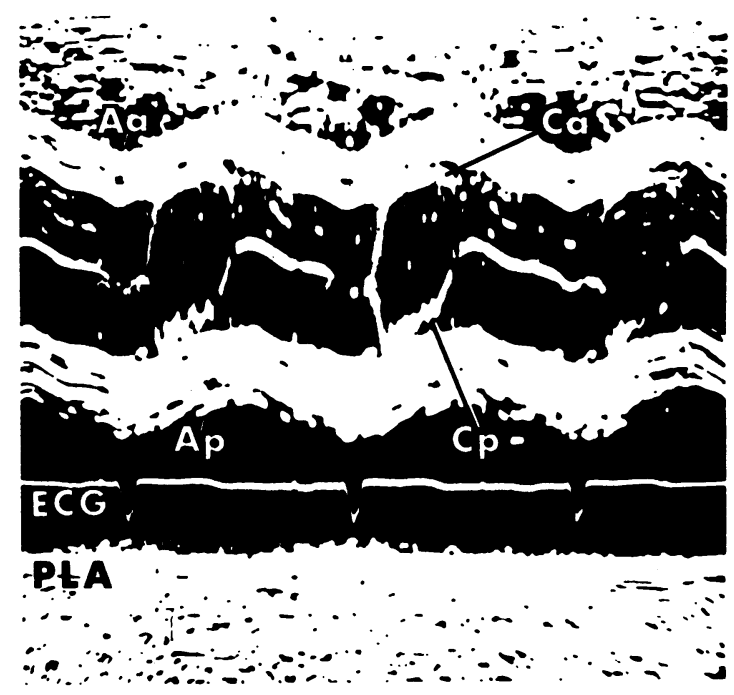

FIG. 9 Shows normal cusp movement from a homograft aortic valve echocardiogram. Other symbols as in Fig. $I$.

of the 35 patients with isolated aortic valve disease who had fresh unstented aortic homograft replacement. The examination was carried out on a single occasion I to 4 weeks (I6 cases) and 96 weeks (I case) after operation. In all instances the homograft valve echocardiogram showed a normal aortic valve pattern (Fig. 9).

The preoperative echocardiographic measurement of the inner aortic root diameter (I I cases) correlated well with the measurements at operation during bypass (Tables 1,2 , and 3 ).

\section{Discussion}

The clinical application of aortic valve echocardiography has not kept pace with that of the mitral valve because of difficulty experienced by several workers in regularly recording meaningful echocardiograms from this valve (Effert et al., 1964; Hernberg et al., 1970; Gramiak and Shah, 1970). The present study has shown that, by using a focused transducer and examining the patients in the left lateral position it is possible to obtain satisfactory aortic valve echocardiograms in over 80 per cent of subjects with normal aortic valves and in the majority of the subjects with diseased aortic valves.

The typical box-like configuration was obtained in $3 I$ per cent of the subjects with normal aortic valves; in $5 \mathrm{I}$ per cent, though the cusps were visualized only in systole and early diastole, this was 
considered to be adequate to exclude valve calcification, thickening, and restricted cusp movement. The frequently observed systolic cusp oscillations presumably indicate increased blood turbulence and pliable cusps.

Clinicopathological studies on patients with circumscribed aortic cusp calcification have confirmed the suggestion of Edler (1964) that the anteriorly visualized echoes are from the right coronary cusp. However, it was found that the posteriorly visualized cusp echoes may represent either the non-coronary or the left coronary cusp.

Tables $I$ and 3 show that aortic valve calcification could be better assessed by echocardiography than by cardiac screening, for the density of cusp echoes correlated better with the assessment of valve calcification at operation. The echocardiographic measurements of the aortic root diameter agreed well with measurements at operation (Tables I, 2, and 3).

In all the patients with calcific aortic stenosis the striking findings were the dense echoes originating from the calcium deposits. The failure to visualize echoes representing valve opening and closure is presumably caused by the density of the above echoes and by the impaired cusp movement. It was not possible to assess the severity of aortic stenosis by echocardiography in these patients, for there was no correlation between the density of the cusp echoes and the aortic valve gradients observed at cardiac catheterization (Table I). Furthermore, recent studies ( $ठ$. Feizi, unpublished observations) in several elderly patients with degenerative aortic valve calcification, without clinical evidence of stenosis, have shown echocardiographic patterns indistinguishable from those of the above patients who had pronounced aortic valve gradients. These observations are not in agreement with those of Gramiak and Shah (1970) who implied that the density of the aortic cusp echoes was an indication of the degree of aortic stenosis.

So far we have had the opportunity of carrying out echocardiography in only one case of aortic stenosis in the absence of cusp calcification (Fig. 5A). This showed a normal systolic position of the cusp signals. The expected reduced separation of the cusp echoes in aortic stenosis was not observed. In this patient the aortic valve was domed. It is presumed that the echoes visualized during systole were from the base of the dome and that the stenosed orifice was displaced upwards out of the reach of the ultrasound beam.

Previous reports of echocardiographic patterns in aortic regurgitation have drawn attention to the secondary effects on the mitral valve echoes, namely fine oscillations of the anterior mitral valve leaflet echoes during diastole (Joyner, Dyrda, and Reid, 1966; Pridie, Benham, and Oakley, 1971). Little information has so far been available on echocardiography of the aortic valve itself in the presence of aortic regurgitation. In the patients studied by Gramiak and Shah (1970) the movement of the aortic cusp echoes was reported to be normal. The only abnormalities recorded were an increase in the aortic root diameter in some of the cases with an important lesion, and increased systolic cusp movement. In the present series, abnormal diastolic separation of aortic cusp echoes was noted in ro out of 15 patients with isolated aortic regurgitation (Table 2). Though diastolic cusp separation was recorded from some normal aortic valves, the degree of separation noted in patients with documented aortic regurgitation was invariably greater than $\mathrm{I} \mathrm{mm}$ and often very much more. The presence of significant diastolic cusp separation can be considered pathognomonic of aortic regurgitation and it has enabled the detection of three silent cases (Table 3).

In Fig. 4A and 5B, diastolic cusp separation which was minimally greater than normal was observed; it is conceivable that these are examples of silent aortic regurgitation. However, angiocardiographic data are not available in these 2 patients. It must be noted that echocardiography does not invariably show diastolic cusp separation in aortic regurgitation, as we noted in one patient (Case 3, Table 2).

In conclusion, echocardiography has proved to be of undoubted value in the detection of aortic valve calcification and thickening, silent aortic regurgitation, and the assessment of cusp mobility. The accurate measurement of the aortic root diameter is also of value. However, contrary to the views of other workers this study has shown that it is not possible to grade the severity of aortic stenosis solely on the echocardiographic appearance of the valve; furthermore it was found to be of limited use in the assessment of some cases of severe aortic regurgitation.

We thank members of the cardiac departments of the Royal Free and the Middlesex Hospitals for their help in the general cardiological investigation of the patients. The technical help of Mr. D. Wagstaff is gratefully acknowledged. This work was supported in part by the Charles Wolfson Foundation.

\section{References}

Edler, I. (1964). Ultrasoundcardiography. In Ultrasound as a Diagnostic and Surgical Tool, p. 124. Ed. by D. Gordon. Williams and Wilkins, Baltimore; Livingstone, Edinburgh and London. 
Edler, I., Gustafson, A., Karlefors, T. and Christensson, B. (196r). Mitral and aortic valve movements recorded by an ultra-sonic echo method: an experimental study. Acta Medica Scandinavica, 170, Suppl. 370, 67.

Effert, S., Bleifeld, W., Deupmann, F. J., and Karitsiotis, J. (1964). Diagnostic value of ultrasonic cardiography. British fournal of Radiology, 37, 920.

Feigenbaum, H. (1972). Clinical applications of echocardiography. Progress in Cardiovascular Diseases, 14, 531.

Gramiak, R., and Shah, P. M. (I968). Echocardiography of the aortic root. Investigative Radiology, 3, 356.

Gramiak, R., and Shah, P. M. (1970). Echocardiography of the normal and diseased aortic valve. Radiology, 96, I.
Hernberg, J., Weiss, B., and Keegan, A. (1970). The ultrasonic recording of aortic valve motion. Radiology, 94, 36r.

Joyner, C. R., Dyrda, I., and Reid, J. M. (I966). Behaviour of the anterior leaflet of the mitral valve in patients with the Austin Flint murmur. Clinical Research, 14, 25 I.

Pridie, R. B., Benham, R., and Oakley, C. M. (I97I). Echocardiography of the mitral valve in aortic valve disease. British Heart fournal, 33, 296.

Requests for reprints to Dr. Ǒ. Feizi, Department of Cardiology, The Middlesex Hospital, Mortimer Street, London WIN 8AA. 